\title{
Effect of Narrowband Ultraviolet B Therapy on Serum Vitamin D in Saudi Patients with Vitiligo
}

Abdulaziz A Alnoshan ${ }^{1 *}$, Amal Al-Najjar², Fatimah M Al-Mutairi and Reem Saad Alsubiae ${ }^{3}$

${ }^{1}$ Department of Dermatology, Security Forces Hospital, Riyadh, Saudi Arabia

${ }^{2}$ Pharmacy Services, Security Forces Hospital Riyadh, Kingdom of Saudi Arabia

${ }^{3}$ College of Pharmacy, Princess Nourah bint Abdulrahman University Riyadh, Kingdom of Saudi Arabia

\begin{abstract}
Objective: To evaluate the effect of NB-UVB therapy on serum levels of 25 -hydroxyvitamin $D[25(\mathrm{OH}) \mathrm{D}]$ in Saudi patients with vitiligo.
\end{abstract}

Method: We estimated the levels of 25-hydroxy vitamin D [25(OH)D] before, and after NB-UVB radiation in patients with vitiligo who did not take vitamin $D$ supplement. A comparison was done between subsets of patients concerning gender and duration of treatment of NB-UVB.

Results: There were 39 patients with vitiligo. Females were $22(56.4 \%)$ and males were $17(43.6 \%)$.The mean vitamin D level before NB-UVB treatment was $29.575 \pm 16.315 \mathrm{nmol} / \mathrm{L}$. while vitamin D level was increased to $78.871+22.776$ after treatment with significant differences $(P<0.0001)$. The males had mean vitamin $D$ level $36.232 \pm 19.505 \mathrm{nmol} / \mathrm{L}$, while females had mean vitamin D level $24.431 \pm 11.321 \mathrm{nmol} / \mathrm{L}$ at baseline. After NB-UVB treatment the males had vitamin $D$ level of $78.888 \pm 25.683 \mathrm{nmol} / \mathrm{L}$. While females had mean vitamin $\mathrm{D}$ level78.859 $\pm 20.884 \mathrm{nmol} / \mathrm{L}$. After 6 months of the NB-UVB treatment the delta change in vitamin D level was $38.888 \pm 20.255$ $\mathrm{nmol} / \mathrm{L}$ while after $12-24$ months of treatment with NB-UVB the delta change in vitamin D level was $60.252 \pm$ $17.565 \mathrm{nmol} / \mathrm{L}(\mathrm{P}=0.001)$.

Conclusion: Patients who received narrow band ultra violet $B$ radiation at wave length $309 \mathrm{~nm}$ as treatment of vitiligo are less likely to need vitamin $D$ supplement to correct their vitamin $D$ deficiency.

More studies are needed in order to confirm these results and to establish UVB as treatment modalities to correct vitamin $\mathrm{D}$ levels in patients who cannot absorb vitamin $\mathrm{D}$ either orally or parentally.

\section{Keywords: Vitiligo; Vitamin D; NB-UVB; Melanogenesis}

\section{Introduction}

Vitiligo is an acquired pigmentary disorder of the skin and mucous membranes that is characterized by circumscribed, depigmented macules and patches. The condition is frequently associated with disorders of autoimmune origin, with thyroid abnormalities being the most common. Several theories have been proposed about the pathogenesis of vitiligo, the precise cause remains unknown. Generally agreed upon principles are an absence of functional melanocytes in vitiligo skin and a loss of histochemically recognized melanocytes, owing to their destruction. However, the destruction is most likely a slow process resulting in a progressive decrease of melanocytes. Theories regarding destruction of melanocytes include autoimmune mechanisms, cytotoxic mechanisms, and an intrinsic defect of melanocytes, oxidant-antioxidant mechanisms and neural mechanisms [1]. Narrow Band Ultraviolet B (NB - UVB) therapy has found favor amongst dermatologists since its first use by Westerhof and NieuweboerKrobotova in the treatment of vitiligo in 1997 because of its safety and efficacy. The mechanism of action of NB-UVB in vitiligo is through induction of immunosuppression and stimulation of the proliferation of melanocytes in the skin and the outer root sheath of hair follicles. There is a stimulatory effect on melanogenesis and on the production of melanocyte stimulating hormones (MSH) [2]. Moreover, several data demonstrate that the UVB portion of the sunlight $(290-320 \mathrm{~nm})$ brings about the photochemical conversion of 7-dehydrocholesterol to previtamin D3 in the stratum spinosum and stratum basale, which is the key step to vitamin D3 synthesis [3]. Vitamin D might have a significant role in NB-UVB induce depigmentation of vitiligo as the correlation between repigmentation of vitiligo lesions and vitamin $\mathrm{D}$ levels increased with increase in duration of phototherapy [3].
Several recent studies have demonstrated that NB-UVB a widely used treatment for skin disorder, significantly improves serum $25(\mathrm{OH})$ $\mathrm{D}$ concentration [4]. Additionally, low-dose nUVB treatment gives a significant increase $(\mathrm{P}<0.001)$ of the vitamin $\mathrm{D}$ status in persons with low initial levels of 25(OH)D [5]. Moreover, there is a difference between effect the UVB and UVA on vitamin D level after treatment with it, phototherapy with UVBnb and UVA/UVBnb increased $25(\mathrm{OH})$ D serum level significantly. However, UVA therapy alone induced a reduction in serum $25(\mathrm{OH})$ concentrations [6].

\section{Aim}

To find and document local data on the influence of NB-UVB therapy on vitamin D serum level among Saudi patients with vitiligo.

\section{Objectives}

1. To describe the correlation between NB-UVB therapy and vitamin $\mathrm{D}$ serum level in patients with vitiligo.

*Corresponding author: Abdulaziz A Alnoshan, Consultant, Head of Dermatology Division, Security Forces Hospital, Riyadh, Kingdom of Saudi Arabia, Tel: +966 50 555 1144; E-mail: aalnoshan@hotmail.com

Received: February 16, 2016; Accepted February 23, 2016; Published February 29, 2016

Citation: Alnoshan AA, Al-Najiar A, Al-Mutairi FM, Alsubiae RS (2016) Effect of Narrowband Ultraviolet B Therapy on Serum Vitamin D in Saudi Patients with Vitiligo. J Pharmacovigilance 4: 198. doi:10.4172/2329-6887.1000198

Copyright: (c) 2016 Alnoshan AA, et al. This is an open-access article distributed under the terms of the Creative Commons Attribution License, which permits unrestricted use, distribution, and reproduction in any medium, provided the original author and source are credited. 
2. To investigate a new modalities of the treatment for patients with vitamin $\mathrm{D}$ deficiency.

\section{Hypotheses}

1. NB-UVB irradiation used in treatment vitiligo patients has no effect on vitamin D serum level.

2. NB-UVB irradiation used in treatment vitiligo patients increases vitamin $\mathrm{D}$ serum level.

\section{Methodology}

The data of this retrospective, observational study was collected from the patients' files at SFHP, Riyadh. This data was collected through, Data collection sheet prepared by the investigators. Including patient's demographic data, clinical information such as past medical history, previous and concomitant medications and results from blood sample tested for $25(\mathrm{OH}) \mathrm{D}$ at baseline and after NB-UVB therapy. The study included 39 patients (17 males and 22 females) of vitiligo with age ranging from 6 - 68 years who were visiting dermatology clinic. Baseline serum 25-hydroxy vitamin D levels were measured in all patients before starting NB-UVB therapy.

NB-UVB phototherapy was given using (Spectra 305 / 350 by Daavlin, 222Piagest. Bryan, Ohio 43506 U.S.A.) at wave length 309 $\mathrm{nm}$. The duration of treatment was between 4 to 24 months. After the course of treatment, the level of $25(\mathrm{OH}) \mathrm{D}$ was measured.

\section{Exclusion and Inclusion Criteria}

\section{Inclusion criteria}

Patients with vitiligo disease treated with NB-UVB therapy, and did not take vitamin $\mathrm{D}$ supplement before or other products that affect vitamin D serum level.

\section{Exclusion criteria}

Any patients has taken a vitamin D supplementation before starting the NB-UVB therapy weather the supplement is from our hospital or from any other source.

Any patient has taken a vitamin $\mathrm{D}$ supplementation at the start (within 2 - 3 weeks) of the NB-UVB therapy.

\section{Data Analysis}

Statistical analysis was performed using Statistical Package for the Social Sciences (SPSS) version 21 software (SPSS Inc., Chicago, ILUSA).We calculated minimum, maximum, mean and standard deviation for numerical variables (measurable variables), and we calculated percentages and frequencies for nominal variables (gender, duration of treatment).We used pair T - test to compare between the level of vitamin D before and after treatment. Also, we used student t-test for independent groups to compare between males and females groups and to compare between patients who had been treated within 4 to 6 months and patients who had been treated within 7 to 24 months with respect to the level of vitamin $\mathrm{D}$ before and after treatment. We assumed there was a statistically significant difference when P-value less than 0.05 .

\section{Results}

The mean age of the 39 patients was 38.08 years (range, 6 - 68 years) who were exposed to treatment period with NB-UVB therapy for an average of mean \pm SD $(8.82 \pm 5.078)$ months (Table 1$),(43.6 \%)$ were men, and $22(56.4 \%)$ were women. We noticed that the percent of vitiligo was more among female $(56.4 \%)$ in our sample $(n=39)$, (Table 2). The difference between short treatment duration ( 4 - 6 months) and long treatment duration (7 - 24 months) among our sample was not significant (Table 3 ).

Vitamin D serum level on the beginning of study with the patients diagnosed with vitiligo who did not take vitamin $\mathrm{D}$ as supplement was $7.38 \mathrm{nmol} / \mathrm{l}$ as minimum level and $70.90 \mathrm{nmol} / \mathrm{l}$ as maximum level (mean $29.57 \mathrm{nmol} / \mathrm{l}$ ). Those patient were exposed to NB-UVB radiation at wave length $309 \mathrm{~nm}$ as treatment modality for their vitiligo for a minimum period of 4 months and a maximum period of 24 months. Resulting in changing of vitamin $\mathrm{D}$ level between $37.91 \mathrm{nmol} / \mathrm{l}$ as a minimum change and $140.40 \mathrm{nmol} / \mathrm{l}$ as a maximum change (mean $78.871 \mathrm{nmol} / \mathrm{l}$ ) as shown in (Table 4), with a significant $\mathrm{P}$ - value $<0.0001$ (Table 5 and Figure 1).

From other point of view, vitamin D serum level was less in females before treatment with NB-UVB therapy $(24.431 \pm 11.321) \mathrm{nmol} / \mathrm{l}$ while in males was $(36.232 \pm 19.505) \mathrm{nmol} / \mathrm{l}$ with significant difference $\mathrm{P}$ - value $=0.023$. However vitamin $\mathrm{D}$ serum level after treatment was the same among males and females (mean 78.88 vs. 78.8591 ) nmol/l,

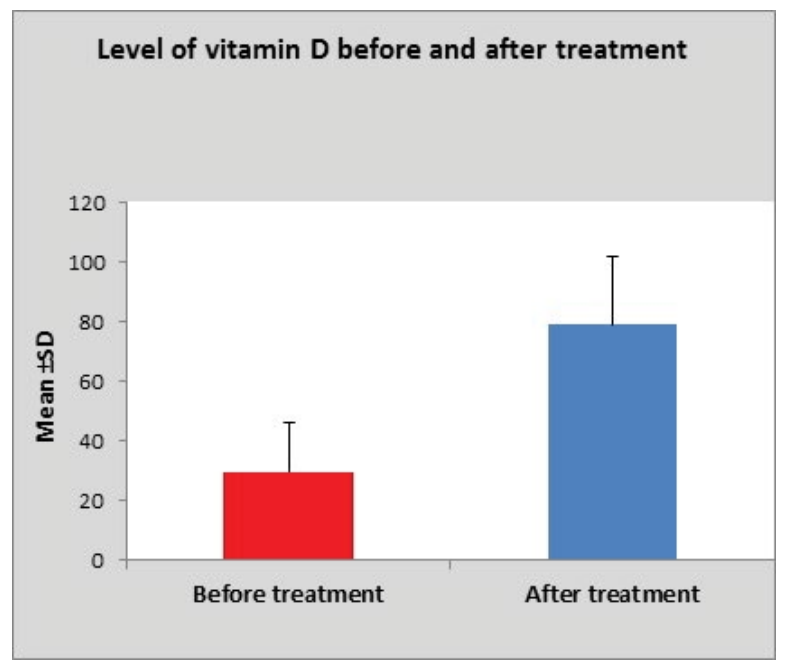

Figure 1: Showing the effect of NB-UVB therapy on Vitamin D serum level.

\begin{tabular}{|c|c|c|c|c|c|}
\hline & N & \multicolumn{2}{|c|}{ Range } & Mean & Std. Deviation \\
\cline { 2 - 5 } & & Minimum & Maximum & & \\
\hline Age (years) & 39 & 6 & 68 & 38.08 & 17.271 \\
\hline $\begin{array}{c}\text { Duration of } \\
\text { treatment (months) }\end{array}$ & 39 & 4 & 24 & 8.82 & 5.078 \\
\hline
\end{tabular}

Table 1: Characteristics of gender and duration of treatment with NB - UVB.

\begin{tabular}{|c|c|c|}
\hline & Frequency & Percent (\%) \\
\hline Male & 17 & 43.6 \\
\hline Female & 22 & 56.4 \\
\hline Total & 39 & 100 \\
\hline
\end{tabular}

Table 2: Gender distribution.

\begin{tabular}{|c|c|c|}
\hline & Frequency & Percent (\%) \\
\hline $4-6$ months & 20 & 51.3 \\
\hline 7 - 24 months & 19 & 48.7 \\
\hline Total & 39 & 100 \\
\hline
\end{tabular}

Table 3: Percentage of duration interval with NB-UVB therapy. 


\begin{tabular}{|c|c|c|c|c|c|}
\hline & \multirow[t]{2}{*}{$\mathbf{N}$} & \multicolumn{2}{|l|}{ Range } & \multirow[t]{2}{*}{ Mean } & \multirow[t]{2}{*}{ Std. Deviation } \\
\hline & & Minimum & Maximum & & \\
\hline Serum 25(OH)D level before treatment with NB-UVB & 39 & 7.38 & 70.9 & 29.575 & 16.315 \\
\hline Serum $25(\mathrm{OH}) \mathrm{D}$ level after treatment with NB-UVB & 39 & 37.91 & 140.4 & 78.871 & 22.776 \\
\hline Delta Change & 39 & 12.16 & 94.6 & 49.296 & 21.64 \\
\hline
\end{tabular}

Table 4: Serum 25-hydroxyvitamin D levels before and after treatment with NB-UVB.

\begin{tabular}{|l|l|l|l|}
\hline & $\begin{array}{l}\text { Before } \\
\text { treatment }\end{array}$ & After treatment & 'P-value \\
\cline { 1 - 3 } & Mean \pm SD & Mean \pm SD & \\
\hline Vitamin D & $29.575 \pm 16.315$ & $78.871 \pm 22.776$ & $\mathrm{P}<0.0001$ \\
\hline B By pair t-test. & & & \\
\hline
\end{tabular}

${ }^{*}$ By pair t-test.

Table 5: Effect of NB-UVB phototherapy on serum 25(OH)D in patients with vitiligo diseases.

and the duration of treatment was almost the same among males and females (mean 8.35 vs. 9.18) months, (Table 6 and Figure 2).

The overall improvement in vitamin D level after NB - UVB treatment there was statistically significant change in the mean vitamin D level. And after 6 months of the NB - UVB treatment, the delta change in vitamin D level was $(38.888 \pm 20.255) \mathrm{nmol} / \mathrm{l}$ while after 12 - 24 months of treatment with NBUVB the delta change in vitamin $\mathrm{D}$ level was $(60.252 \pm 17.565) \mathrm{nmol} / \mathrm{l}(\mathrm{P}-$ value $=0.001)($ Table 7 and Figure 3).

\section{Discussion}

Approximately, $0.1-2 \%$ of the world's population is currently affected by vitiligo [7]. Various factors have been implicated in the etio-pathogenesis vitamin-D receptor-Apa-1 polymorphism [8], and low levels of circulating 25-OH vitamin D [9]. Vitamin D insufficiency is common in Kingdom of Saudi Arabia in spite of good sunshine throughout the year. Vitamin D is produced by UVB in the skin and can also be provided by dietary sources such as fat fish [10]. Vitamin D is considered to be the precursor of a hormone (1,25-dihydroxyvitamin $\mathrm{D}, 1,25(\mathrm{OH}) 2 \mathrm{D})$, which plays a role for bone health, autoimmune diseases, cardiovascular diseases and cancer $[11,12]$. Moreover, there are different mechanisms by which vitamin $\mathrm{D}$ may help treat Vitiligo. Vitamin $\mathrm{D}$ can suppress the activation of $\mathrm{T}$ cells and the release of cytokines such as TNF-alpha (tissue necrosis factor alpha). Because vitamin D suppresses some cells of the immune system, it can protect melanocytes against autoimmune attack. And by promoting the differentiation and proliferation of melanocytes, vitamin $\mathrm{D}$ ensures that the production of new melanocytes exceeds the rate at which old melanocytes are dying and have antioxidant properties [13]. Interestingly, patients receiving NB-UVB radiation have shown an increase in the levels of $25(\mathrm{OH})$ vitamin D [14]. Vitamin D at cellular level modulates melanogenesis [15].The results of our study that reveals of serum $25(\mathrm{OH}) \mathrm{D}$ was elevated following NB-UVB treatment in vitiligo patients. Before treatment vitamin $\mathrm{D}$ serum level was Mean \pm SD $(29.575 \pm 16.315 \mathrm{nmol} / \mathrm{l})$ and after treatment was $(78.871$ $\pm 22.776 \mathrm{nmol} / \mathrm{l})$ with significant $\mathrm{p}$ - value $(\mathrm{P}<0.0001)$. Our findings are in agreement of previous studied who found an increase in the levels of $25(\mathrm{OH})$ vitamin $\mathrm{D}$ by treatment with NB-UVB $[16,17]$. We found that the levels of $25(\mathrm{OH})$ vitamin $\mathrm{D}$ were more after 6 months of treatment and still more after 12-24 months of treatment. And there was a statistically significant ( $\mathrm{p}$ - value 0.001 ) with prolonged treatment. Other study confirm that the vitamin D levels increased with increase in duration of phototherapy [3].There was a gender dimorphism among patients with vitiligo and levels of $25(\mathrm{OH})$ vitamin D were more in males gender than females. However the magnitude of response was more marked in females. And the delta change was $54.428 \pm 19.734$ which was higher than delta change in males. Other studies revealed that the increase of $25(\mathrm{OH}) \mathrm{D}$ was largest in the patients with the lowest baseline values [18-20].

The limitations of the study are the relatively small number of patients included and the wide age range of the patients. In addition, some factors, such as sun exposure and clothing habits, could have some influence on the results.

\section{Conclusion}

Patients who received ultra violet B therapy at wave length $309 \mathrm{~nm}$ as treatment of vitiligo are less likely to need vitamin D supplement to correct their vitamin D deficiency. More studies are needed in order to confirm these results and to establish UVB as treatment modalities to correct vitamin D levels in patients who cannot absorb vitamin D either orally or parentally.

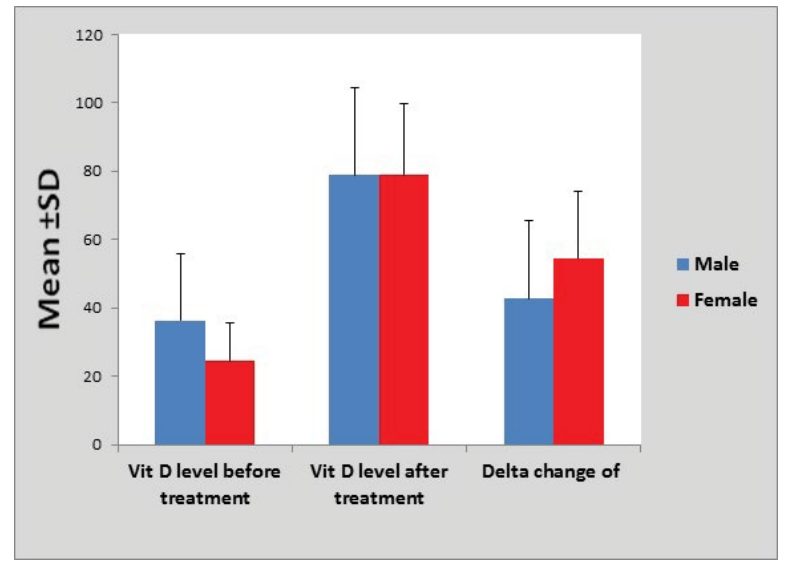

Figure 2: Showing improvement in vitamin D serum levels after NB-UVB therapy pertaining to the gender of the patients.

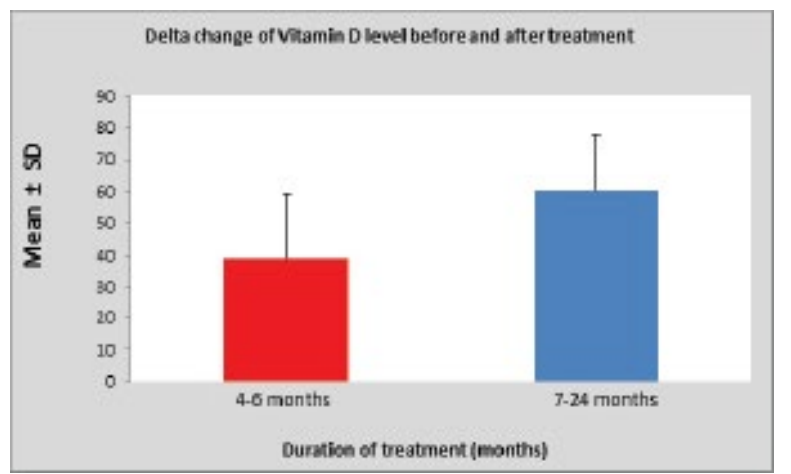

Figure 3: Magnitude of improvement vitamin $D$ in vitiligo patients in relation to the duration of treatment. 
Citation: Alnoshan AA, Al-Najjar A, Al-Mutairi FM, Alsubiae RS (2016) Effect of Narrowband Ultraviolet B Therapy on Serum Vitamin D in Saudi Patients with Vitiligo. J Pharmacovigilance 4: 198. doi:10.4172/2329-6887.1000198

Page 4 of 4

\begin{tabular}{|c|c|c|c|}
\hline & \multicolumn{2}{|l|}{ Gender } & \multirow[t]{3}{*}{ "P-value } \\
\hline & Males $(n=17)$ & Females $(n=22)$ & \\
\hline & Mean \pm SD & Mean \pm SD & \\
\hline Vit D serum level before NB-UVB therapy. & $36.232 \pm 19.505$ & $24.431 \pm 11.321$ & 0.023 \\
\hline Vit D serum level after NB-UVB therapy. & $78.888 \pm 25.683$ & $78.859 \pm 20.884$ & 0.997 \\
\hline Delta change of Vitamin D & $42.655 \pm 22.759$ & $54.428 \pm 19.734$ & 0.092 \\
\hline Duration of treatment & $8.35 \pm 5.623$ & $9.18 \pm 4.717$ & 0.620 \\
\hline
\end{tabular}

Table 6: Showing improvement in Vitamin D levels after NB-UVB pertaining to the gender of the patients.

\begin{tabular}{|c|c|c|c|}
\hline & \multicolumn{2}{|l|}{ Duration of $\mathrm{Tx}$} & \multirow[t]{3}{*}{ 'P-value } \\
\hline & $4-6$ months $(n=20)$ & $7-24$ months $(n=19)$ & \\
\hline & Mean \pm SD & Mean \pm SD & \\
\hline $\begin{array}{l}\text { Delta change of Vitamin D level } \\
\text { before and after treatment }\end{array}$ & $38.888 \pm 20.255$ & $60.252 \pm 17.565$ & 0.001 \\
\hline
\end{tabular}

BBy student t-test for independent groups

Table 7: Overall improvement in vitamin D serum level after NB-UVB treatment according to the duration of treatment.

\section{References}

1. Groysman V, Sami N (2015) Vitiligo. Medscape.

2. Njoo MD, Spuls PL, Bos JD, Westerhof W, Bossuyt PMM (1998) Nonsurgical repigmentation therapies in vitiligo: meta-analysis of the literature. Arch Dermatol 134:1532-1540.

3. Sehrawat M, Arora TC, Chauhan A, Kar HK, Poonia A, et al. (2014) Correlation of vitamin D levels with pigmentation in vitiligo patients treated with NBUVB Therapy. ISRN Dermatology 2014.

4. Ala-Houhala MJ, Karppinen $\mathrm{T}$, Vähävihu K, Kautiainen $\mathrm{H}$, Dombrowski $\mathrm{Y}$, et al (2014) Narrow-band ultraviolet B treatment boosts serum 25-hydroxyvitamin D in patients with psoriasis on oral vitamin D supplementation. Acta Derm Venereol 94: 146-151.

5. Cicarma E, Mørk C, Porojnicu AC, Juzeniene A, Tam TT, et al. (2010) Influence of narrowband UVB phototherapy on vitamin D and folate status. Exp Dermatol 19: e67-72.

6. Feldmeyer L, Shojaati G, Spanaus KS, Navarini A, Theler B, et al. (2013) Phototherapy with UVB narrowband, UVA/UVBnb, and UVA1 differentially impacts serum 25-hydroxyvitamin-D3. J Am Acad Dermatol 69: 530-536.

7. Halder RM, Taliaferro SJ. Vitiligo in Fitzpatrick's Dermatology in General Medicine.

8. Zhang XJ, Chen JJ, Liu JB (2005) The genetic concept of vitiligo. J Dermato Sci 39: 137-146.

9. Silverberg JI, Silverberg Al, Malka E, Silverberg NB (2010) A pilot study assessing the role of 25 hydroxy vitamin $D$ levels in patients with vitiligo vulgaris. J Am Acad Dermatol 62: 937-941.

10. Chen TC, Chimeh F, Lu Z, Mathieu J, Person KS, et al. (2007) Factors that influence the cutaneous synthesis and dietary sources of vitamin D. Arch Biochem Biophys 460: 213-217.
11. Holick MF (2004) Sunlight and vitamin D for bone health and prevention of autoimmune diseases, cancers, and cardiovascular disease. Am J Clin Nutr 80: 1678S-1688S.

12. Tsoukas CD, Provvedini DM, Manolagas SC (1984) 25-dihydroxyvitamin D3: a novel immunoregulatory hormone. Science 224: 1438-1440.

13. Vitamin $\mathrm{D}$ for vitiligo.

14. Lim HW, Carucci JA, Spencer JM, Rigel DS (2007) Commentary: A responsible approach to maintaining adequate serum vitamin D levels. J Am Acad Dermatol 57: 594-595.

15. Watabe H, Soma Y, Kawa Y, Ito M, Ooka S, et al. (2002) Differentiation of murine melanocyte precursors induced by, 25-Dihydroxyvitamin D3 is associated with the stimulation of endothelin B receptor expression. Journal of Investigative Dermatology 119: 583-589.

16. Vähävihu K, Ylianttila L, Kautiainen $\mathrm{H}$, Viljakainen $\mathrm{H}$, Lamberg-Allardt $\mathrm{C}$, et al. (2010) Narrowband ultraviolet B course improves vitamin D balance in women in winter. Br J Dermatol 162: 848-853.

17. Al-Mutairi N, Shaaban D (2014) Effect of narrowband ultraviolet B therapy on serum vitamin $D$ and cathelicidin (LL-37) in patients with chronic plaque psoriasis. J Cutan Med Surg 18: 43-48.

18. Bogh MK, Schmedes AV, Philipsen PA, Thieden E, Wulf HC (2011) Vitamin D production depends on ultraviolet-B dose but not on dose rate: a randomized controlled trial. Exp Dermatol 20: 14-18.

19. Bogh MK, Schmedes AV, Philipsen PA, Thieden E, Wulf HC (2010) Vitamin D production after UVB exposure depends on baseline vitamin D and total cholesterol but not on skin pigmentation. J Invest Dermatol 130: 546-553.

20. Moan J, Lagunova Z, Cicarma E, Aksnes L, Dahlback A, et al. (2009) Sunbeds as vitamin D sources. Photochem Photobiol 85: 1474-1479. 